\title{
Fostering Learner Autonomy in ESL Teaching
}

\section{Mingxia Liu}

\author{
Shandong University of Technology, China
}

\begin{abstract}
As we all know, changes in the field of language teaching have never stopped. Among the changes that took place in recent years, the main one has been a shift of focus from teachers onto the language learners. Learner autonomy is the new 'buzz-word' in the field of applied linguistics. How to cultivate LA becomes a key concern for educators and researchers. In order to know whether the LA
\end{abstract} could be cultivated and the cultivation of LA could benefit the students or not, the author carried out an experiment in Grade One in the Mathematics and Information School in Shandong University of Technology. The experiment was carried out in one year in two classes. The instruments used in the experiment were a questionnaire and three examination papers. The questionnaire which was adapted from Nunan (1996) and modified by the writer included 27 items concerning autonomous learning. The results of the questionnaire and the grades of the three examinations were collected and analyzed to find out whether LA could be cultivated and whether the cultivation of autonomous learning would benefit the students' English learning. Analysis of the quantitative data was performed on the computer using SPSS. Our conclusion is that LA could be cultivated and the cultivation of LA benefited the students' English learning. The thesis included the methodology used in the experiment, the procedure, data analysis and pedagogical implications we could get from the study.

Keywords- learner autonomy, autonomous learning, ways to foster.

\section{INTRODUCTION}

All language teachers have been seeking the most effective way to help their students be more proficient in language learning, and have tried one method after another. It was realized that they had long been pursuing a perfect teaching method, which attached much importance to only one side of learning — the teacher, while the other side, the subject of learning - the large number of learners, was neglected. Being aware of this, many language teachers gradually began to develop their interest in considering the task from the learner's point of view and shift their focus of classroom from a teacher-centered one to a learner-centered one. Learner autonomy, which is the central point of my thesis, refers to the ability to take full responsibility for the decisions with one's own learning and the accomplishment of those decisions (Dickinson 1987:11). In the classroom, instead of being passively guided by the teacher, the student tries to get the best out of classroom teaching according to both the teacher's and his own objectives. Outside the classroom, he makes reasonable plans concerning his learning and implements these plans.

\section{A RESEARCH ON FOSTERING LEARNER AUTONOMY}

\subsection{Research Questions and Hypothesis}

\subsubsection{Research Questions}

The study reported here adopted a case study approach to investigate current ELT in China for both inside and outside English classroom from the perspective of learner autonomy. The study is intended to find answers to the following research questions:

1. Can LA be cultivated?

2. Will the cultivation of LA benefit the students' English Learning?

\subsubsection{Hypothesis}


This study attempted to test the hypothesis. The hypothes is is put forward on the basis of field research.

A. Alternative hypothesis $\left(\mathrm{H}_{1}\right)$ :

LA can be cultivated and the cultivation of LA will benefit the students'English Learning.

B. Null hypothesis $\left(\mathrm{H}_{0}\right)$ :

LA cannot be cultivated and the cultivation of LA will not benefit the students'English Learning.

\subsection{Methodol ogy}

\subsubsection{The Subjects and the Design of the Experiment}

161 students of mathematics school from Shandong University of Technology in two classes took part in the experiment .The experiment was carried out in one year in two classes. One is Experimental Class (EC) and another is Control Class (CC). A questionnaire including 27 items concerning autonomous leaning was handed out to the students for three times. The students had examinations each time after the questionnaire was handed out. The students in the EC was trained on learning strategies and motivated to be interested in English learning. So me related information about autonomous learning was also introduced to the students, such as the necessity of making a plan and supervising the carrying out of the plan, the importance of self-monitoring and self-assessment. The $\mathrm{CC}$ will just have regular classes. The results of the questionnaire and the marks of the three examinations will be collected and analyzed to find out whether the null hypothesis $\left(\mathrm{H}_{0}\right)$ is correct or the alternative hypothes is $\left(\mathrm{H}_{1}\right)$ is correct.

\subsubsection{Experimental Instruments}

\subsubsection{Questionnaire}

Adapted from Nunan (1996) which gives an example of the type of activities that could take place in class to sensitize learners to their learning styles, the questionnaire includes 27 items (Appendix). The author of this thesis made some necessary changes combining the questionnaire on learning strategies. All these 27 items tested the students on their motivation, the style of classroom organization, cognitive strategies, metacognitive strategies; communicative strategies and resource strategies (see Table 1). Each of these items is followed by five alternatives on a 5-point Likert scale scoring from 1(strongly agree) to 5 (strongly disagree). In order to have the content validity of the measure, it was given to three other experienced English teachers who all work on applied linguistics for their comments. They suggested some modifications. And upon their recommendation, some items were revised.

Table.1: Questionnaire Items within Each Category

\begin{tabular}{|l|l|}
\hline \multicolumn{1}{|c|}{ Category name } & \multicolumn{1}{c|}{ Item No. } \\
\hline Motivation & $20,21,22,23,27$ \\
\hline Clas sroom organization & $3,4,5$ \\
\hline Cognitive strategies & $11,12,14,24$ \\
\hline Metacognitive strategies & $6,7,8,9,10,13$ \\
\hline Communicative strategies & $1,2,25,26$ \\
\hline Resource strategies & $15,16,17,18,19$ \\
\hline
\end{tabular}

\subsubsection{Tests}

The students took part in three examinations. The three test papers used for the examinations were all made in groups by the experienced teachers in Shandong University of Technology. The students could be tested in listening, reading, and writing. The students could be tested on integrating skills in using English. In the author's opinion, there are three reasons to prove that the papers are valid. First, they were made in groups by the experienced teachers. They were asked to reflect the common level of the students. Second, they had the same style as CET-4, which is considered to be the most widely acceptable way to test students' level. Although some people argued that it could not reflect the learners' real English level, CET is still a very important part in the college examination. Third, all the students in Grade one used the same test papers and the papers were read over and given marks by the teachers in groups.

\subsubsection{Experimental Procedures}

\subsubsection{Procedures}

The experiment was carried out in one year. Two 
classes were chosen. The same English teacher, the author of the thesis, taught both of the two classes. In the Experimental Class (EC), the teacher tried to arouse the students' interest in learning English, get them to know the importance and aim of English learning, ask them to make plans for their learning and monitor the carry ing out of the learning plans (details in 2.4.2). The teacher also kept abreast of the students learning styles and trained the students for learning strategies while giving them lessons. Then at last, the students together with the teacher assessed the results of their learning. While the Control class (CC) just had the regular classes.

The questionnaires were handed out to the students three times to find out whether LA could be cultivated. The Pre-test and the Mid-test questionnaires were handed out before the mid-term and the end-term examination in the first term. The post-test questionnaires were handed out before the end-term examination in the second term. Each time after the questionnaires were given to the students, the students had an examination and the marks were collected. The three examinations were the mid-term (Test 1), the final-term (Test 2) examinations in the first term and the final-term examination (Test 3 ) in the second term.

After collecting all the data needed, analysis was made according to the test papers marks and the questionnaire results.

\subsubsection{Teaching Methods and Activities}

In the procedure of developing the learners into independent learners, the author used the teaching methods and activities stated in the following 12 items in everyday English teaching. Emphasis was put on the shift of responsibilities, active learning, cooperative learning and the extended reading materials the learners should refer to

1. Making a proper plan at the beginning of a new term. Supervising its implement both by the teachers and the learners themselves. The supervising process would raise the learners' awareness that responsibility for learning rests with them.
2. Picking out some passages from the textbook and ask the students to act as teachers and teach the passages to the other students. Before teaching, the students must make good preparations including the content of the passages and explanations for some language points in the text. Some students were really knowledgeable in some subjects and the others would be aroused by their excellent performance.

3. Giving some questions to the students to think about before performing a certain task. For example, asking the students to guess what would be talked about in the listening material before playing the tape. In this way, the students could learn more effectively because of this thinking while learning.

4. Motivating and activating their interest in learning. To do this, the teachers should try to understand the students and get to know what their interest is. Having an informal discussion and personal communication with the students are easy to know more about the students.

5. Short performances before every class, including dialogues, short plays, introducing some good poems and essays are all colorful and interesting ways of starting class. These activities would ensure that every student took part in the activity in English in class.

6. Sometimes when a question was raised in class, the students could be asked to give correct answers, not the teachers. In this way, the teachers would find out how well the students had learned. At the same time, the other students could also be activated by the students who were able to answer the questions.

7. Asking the students to retell the text they have learned. They could also act out some of the passages. Or maybe the students could choose some other topics they were interested in, such as things happened in everyday life and some fairy tales.

8. Asking the students to finish their homework by 
themselves. First, correct the possible mistakes in pairs or in small group, then check the mistakes by themselves again and hand in the homework to the teacher. By Learning from mistakes, it's much quicker, much more convenient and more effective for the students to get the correct knowledge.

9. In order to lead the students to love English and be more interested in English, different kinds of competitions could be held. Such as, reading competition, oral English competition, comprehensive competition and so on. These were different from tests and the students would feel less anxious and more interested.

10. Helping the students monitor and assess their progress and retrogress. Helping them to find out their advantages and disadvantages. And most important, helping them to fully bring out their latent potentialities and affirm their achievements.

11. Encouraging the students, especially some top students to adjust the process and degree of difficulty of their learning materials according to their own needs.

12. Making it clear to the students that reading is a good way in English learning. Encouraging them to do some extra reading. Novels, magazines and newspapers can all help them to meet the requirement on reading.

By doing this, both the teacher and the students would change their attitudes towards the roles they played. The teacher was no longer the center of the classroom teaching. Instead, the teacher was the mediator, facilitator, organizer, counselor, source of information and evaluator. The teacher also gave feedbacks to the students' learning methods, strategies and achievements. The students were not passive receivers. They began to accept the idea of being the masters of their own learning and gradually took the responsibility of learning by themselves. They knew what they wanted to learn, what they didn't know. They made plans for their own learning, monitored the carrying out of the plans, assessed and evaluated their learning. The learners used learning strategies taught by the teacher first purposely as a way to facilitate their learning and gradually the strategies became their potential ability in language learning. The learners changed from individual learners to co-operatives.

\subsection{Data Analysis}

T-test was used to analyze the data. Analysis of the quantitative data was run on the computer using SPSS for Windows (Version10.0). First, descriptive statistics were calculated for the original Test (OT), Test 1, Test 2 and Test 3 (Table 2) to find out if the students in the EC got higher marks than the students in the students in the CC. Second, descriptive statistics were calculated for Pre-test, Mid-test and Post-test to compare the changes between the two classes (Table 6) and see if the result agrees with that in Table 3 and Table 4. For the three different times, the questionnaire categories were named as Motivation 1, Motivation 2 and Motivation 3. Other categories were named in the same way.

T-test was used to analyze the original marks $(\mathrm{OM})$ of the Experimental Class (EC) and the control Class (CC). This test was used to find out whether there was any difference between the two classes at the beginning of the experiment. The findings were the following:

Table.2: Descriptive Statistics of the Original Test for the EC and CC

\begin{tabular}{|c|c|c|c|l|l|}
\hline Class & \multicolumn{1}{|c|}{$\mathrm{N}$} & Minimum & Maximum & Mean & Std. Deviation \\
\hline Experimental Class & 82 & 50.00 & 112.50 & 97.38 & 14.05 \\
\hline Control Class & 79 & 34.50 & 114.00 & 96.60 & 15.94 \\
\hline
\end{tabular}

In the original test, the observed $\mathrm{t}$ - value is 1.90 , which was significant because the observed significance level was $0.965(\mathrm{p}>0.05)$, and the observed $\mathrm{t}-$ value $1.90<$ the given $\mathrm{t}$.
This result shows that there was no significant difference between the two classes in the original test.

This t-test was carried out to find out how well the two 
groups did in the tests and whether there was any after treatment. The following are the results:

significant difference between the means of the two classes

Table.3: Descriptive Statistics of the Tests for the EC

\begin{tabular}{|l|l|l|l|l|l|l|}
\hline \multirow{2}{*}{ Class } & Total & \multicolumn{5}{|c|}{ Experimental Class } \\
Marks & & \multicolumn{5}{|c|}{} \\
\cline { 3 - 7 } & & $\mathrm{N}$ & Mini & Maxi & Mean & $\begin{array}{c}\text { Std. } \\
\text { Deviation }\end{array}$ \\
\hline OT & 150 & 82 & 50.00 & 112.50 & 97.38 & 14.05 \\
Test 1 & 150 & 82 & 51.00 & 135.00 & 101.65 & 17.12 \\
Test 2 & 150 & 82 & 60.00 & 129.00 & 97.81 & 11.75. \\
Test 3 & 150 & 82 & 54.00 & 138.00 & 105.40 & 11.14 \\
Valid N & 150 & 82 & & & & \\
(listwise) & & & & & & \\
\hline
\end{tabular}

(Notes: The 100 - point grading system in the three tests was changed into 150 - point for the convenience of statistical analys is )

Table.4: Descriptive Statistics of the Tests for the CC

\begin{tabular}{|c|c|c|c|c|c|c|}
\hline \multirow{2}{*}{ Examinatio } & \multirow{2}{*}{$\begin{array}{l}\text { Total } \\
\text { Marks }\end{array}$} & \multicolumn{5}{|c|}{ Control Class } \\
\hline & & $\mathrm{N}$ & Mini & Maxi & Mean & $\begin{array}{c}\text { Std. } \\
\text { Deviation }\end{array}$ \\
\hline OT & 150 & 79 & 34.50 & 114.00 & 96.60 & 15.95 \\
\hline Test 1 & 150 & 79 & 43.50 & 133.50 & 95.66 & 20.92 \\
\hline Test 2 & 150 & 79 & 36.00 & 123.00 & 93.02 & 16.04 \\
\hline Test 3 & 150 & 79 & 40.50 & 133.50 & 100.02 & 18.33 \\
\hline $\begin{array}{l}\text { Valid N } \\
\text { (listwise) }\end{array}$ & 150 & & & & & \\
\hline
\end{tabular}

In Test 1 , the observed $\mathrm{t}$ - value is 1.98 , which was significant because the observed significance level was $0.048(\mathrm{p}<0.05)$ and the observed $\mathrm{t}>$ the given $\mathrm{t}$-value. Besides, the mean of the EC 101.65> 95.66, the mean of the CC.

In Test 2, the observed $\mathrm{t}$ - value is 2.01 , which was significant because the observed significance level was $0.032(\mathrm{p}<0.05)$ and the observed $\mathrm{t}>$ the given $\mathrm{t}$-value. Besides, the mean of the EC 97.81>93.02, the mean of the CC.
In Test 3, the observed t- value is 2.46 , which was significant because the observed significance level was $0.01(\mathrm{p}<0.05)$ and the observed $\mathrm{t}>$ the given $\mathrm{t}$-value. Besides, the mean of the EC 101.65> 100.02, the mean of the CC.

Then it is safe to draw the conclusion that there was significant difference between the two classes in the Test 1 , Test 2 and Test 3.

Independent-Sample Test was used to find out after one-year-training on LA whether the students in EC had got 
the ability to learn autonomously and could do better in their English learning. For this reason, the author intended to compare the examination marks between EC and CC. Test 1, Test 2 and Test 3 marks were all collected. The results are shown in Table 5, Table 6 and Table 7. From Table 5, we can see the mean marks of OT for the EC (97.38) and the CC (96.60) are almost the same and the distance of Std. Deviations is 1.90 .

In Test 1 , the distance of mean marks between the two classes is 5.99 , but there is a large distance between the Std. Deviations, which is 3.80 . In Test 2 , the distance of mean marks between the two classes is 4.79, but he Std. Deviation distance is still larger 4.29. In Test 3, the distance of mean marks between the two classed is 5.38 and the Std. Deviation's distance is 7.19. From the statistics we can see the students in EC did better. The Std. Deviations show that most of the students in EC got marks near to the means. But in Test 1 , the Std. Deviation is 17.12 , which is much larger than 11.75 in Test 2 and 11.14 in Test 3. When we look at the Std. Deviation in the CC, we can see they are all larger than those of the EC. So we can draw the conclusion that most of the students in EC have make progress in their English learning after the training LA.

Table.5: The Distances of the Mean Marks and Std.

Deviations between EC and CC

\begin{tabular}{|l|l|l|}
\hline & Mean & \multicolumn{1}{|c|}{$\begin{array}{c}\text { Std. } \\
\text { Deviation }\end{array}$} \\
\hline Original test & 0.78 & 1.90 \\
Test 1 & 5.99 & 3.80 \\
Test 2 & 4.79 & 4.29 \\
Test 3 & 5.38 & 7.19 \\
\hline
\end{tabular}

Table.6: Descriptive Statistics of the Questionnaire

\begin{tabular}{|c|c|c|c|c|c|c|c|c|c|c|c|}
\hline & \multirow{2}{*}{$\begin{array}{l}\text { Total } \\
\text { grades }\end{array}$} & \multicolumn{5}{|c|}{ Experimental Class } & \multicolumn{5}{|c|}{ Control Class } \\
\hline & & $\mathrm{N}$ & Mini & Maxi & Mean & $\begin{array}{l}\text { Std. } \\
\text { Deviation }\end{array}$ & $\mathrm{N}$ & Mini & Maxi & $\begin{array}{l}\text { Mea } \\
n\end{array}$ & $\begin{array}{l}\text { Std. } \\
\text { Deviation }\end{array}$ \\
\hline M1 & 30 & 80 & 8.40 & 22.80 & 14.31 & 3.5289 & 76 & 8.40 & 26.40 & 14.77 & 3.5242 \\
\hline M2 & 30 & 81 & 5.00 & 22.00 & 11.33 & 3.3415 & 78 & 7.00 & 30.00 & 14.27 & 5.7262 \\
\hline M3 & 30 & 82 & 7.20 & 22.80 & 14.72 & 3.3448 & 76 & 8.40 & 22.80 & 15.36 & 3.3482 \\
\hline $\mathrm{CO} 1$ & 30 & 80 & 10.0 & 30.00 & 17.62 & 4.8841 & 76 & 6.00 & 30.00 & 18.74 & 5.4847 \\
\hline $\mathrm{CO} 2$ & 30 & 82 & 0 & 24.00 & 15.92 & 3.8021 & 76 & 6.00 & 22.00 & 14.81 & 3.9855 \\
\hline $\mathrm{CO} 3$ & 30 & 82 & 6.00 & 28.00 & 15.85 & 3.6500 & 76 & 8.00 & 26.00 & 17.89 & 4.3161 \\
\hline CS1 & 30 & 82 & 8.00 & 24.00 & 15.00 & 3.7210 & 78 & 6.00 & 24.00 & 17.18 & 7.2676 \\
\hline $\mathrm{CS} 2$ & 30 & 82 & 7.50 & 25.00 & 14.86 & 4.3560 & 76 & 7.50 & 27.00 & 16.39 & 4.6312 \\
\hline CS3 & 30 & 82 & 7.50 & 27.00 & 15.83 & 4.0822 & 78 & 9.00 & 25.00 & 17.32 & 3.3562 \\
\hline MCS1 & 30 & 80 & 6.00 & 21.00 & 12.94 & 2.7625 & 76 & 8.00 & 21.00 & 14.20 & 2.8310 \\
\hline MCS2 & 30 & 82 & 8.00 & 22.00 & 16.06 & 2.9490 & 76 & 11.00 & 30.00 & 17.74 & 5.3348 \\
\hline MCS3 & 30 & 82 & 9.00 & 20.00 & 12.90 & 2.6634 & 76 & 7.00 & 22.50 & 13.58 & 2.6627 \\
\hline CMS1 & 30 & 82 & 8.00 & 27.00 & 18.14 & 4.3264 & 78 & 6.00 & 30.00 & 17.97 & 4.3444 \\
\hline CMS2 & 30 & 82 & 7.50 & 24.00 & 16.79 & 3.0444 & 79 & 7.50 & 22.50 & 16.56 & 3.3346 \\
\hline CMS3 & 30 & 82 & 9.00 & 25.50 & 16.68 & 3.1349 & 79 & 6.00 & 30.00 & 18.31 & 4.9224 \\
\hline RS1 & 30 & 82 & 12.0 & 26.40 & 15.28 & 4.6186 & 79 & 6.00 & 30.00 & 16.40 & 5.2695 \\
\hline
\end{tabular}




\begin{tabular}{|l|l|l|l|l|l|l|l|l|l|l|l|} 
RS2 & 30 & 82 & 0 & 30.00 & 15.74 & 4.6515 & 78 & 6.00 & 30.00 & 18.70 & 5.4976 \\
RS3 & 30 & 82 & 6.00 & 22.00 & 15.19 & 5.5258 & 78 & 6.00 & 30.00 & 16.59 & 4.5429 \\
Valid N & 30 & 80 & 6.00 & & & & 40 & & & & \\
& & & 6.00 & & & & & & & & \\
\hline
\end{tabular}

M stands for Motivation

$\mathrm{CO}$ stands for Clas room Organization

CS stands for Cognitive strategies

MCS stands for Metacognitive Strategies

CMS stands for Communicative Strategies

RS stands for Resource Strategies

From Table 6, when comparing the EC with the $\mathrm{CC}$, the author found that for most of the categories, the means are smaller in the EC than in the CC (The smaller the statistics are, the better the students employ the training strategies). But the means for Commun icative Strategies 1, 2 and 3 in the EC are all larger than those in the CC and the Std. Deviation are all smaller. From this we can draw the conclusion that the students in the EC didn't do well in employing the Communicative Strategies, although they did well in the training of the other categories. That is to say, the students in the EC didn't like to communicate with others and used English as a tool both in class and after class (see Appendix 1, 2, 25, and 26). This is a field we should pay more attention to. When we refer to the means of Pre-test, Mid-test and Post-test in the EC, we can see that at the end of the experiment, in the Post-test, except for the means for Motivation 3 and Cognitive Strategies 3, the means for Classroom Organization 3, Metacognitive Strategies 3, Communicative Strategies 3 and Resource' Strategies 3 in the EC are all lower than those in Pre-test and Mid-test. Thinking of the above analyses for the Examinations, which show that the students made some progress in their examinations, we can see that the training strategies are helpful in cultivating the learners' LA and the cultivation benefit the students'English learning.

\subsection{Findings}

From the above analysis, we can see that after being trained for learning strategies to get the ability to learn autonomously, the students in the EC made some progress in their English learning. The students could be trained to learn autonomously and the cultivation of LA benefited the students' English learning. So our alternative hypothesis is correct but the null hypothesis is wrong.

From the above analysis, we can also say that at the end of the experiment, the students in the EC made some progress in their English learning. We can see this from their scores in the examinations. The items in the questionnaire and the 12 training strategies in everyday English teaching helped some students do better in a range of language learning tasks and somehow have the ability to become autonomous learners. Our alternative hypothesis is correct. The students can be trained to learn autonomously and the cultivation of LA benefits the students' English learning. Both in the EC and the CC, the students get higher scores in Communicative Strategies (The higher the scores are, the worse the students do in learning autonomously). It shows that although the learners can make some progress in taking part in examinations after beings trained for LA: they didn't like to communicate with others and use English as a tool both in class and after class even after the training. This may have some relationship with affective and social aspects, such as personalities, motivation, the learning context and purpose for learning the language (Oxford 1990). Oxford (1990) sees the aim of language learning strategies as 
being oriented towards the development of commun icative competence and that they must, therefore, involve interactions among learners. Learning strategies must both help learners to participate in communication and to build up their language system. This study has in some degree reached the goal of helping the learners to learn to learn, but has not been successful in motivating the learners to participating in communication.

\section{CONCLUSION}

My thesis is only a preliminary study of learner autonomy, which is a comparatively new field of interest in applied linguistics. It attempts to promote autonomy in Chinese university students in the study of a foreign language. From above experiment, we can see that after being trained for learning strategies to get the ability to learn autonomously, the students in the EC made some progress in their English learning. The students could be trained to learn autonomously and the cultivation of LA benefited the students' English learning. With the maturing of learner training program in China, students will take more responsibility for their learning and enter into learning more purposely and effectively.

In a word, we should have a full understanding of the superiority of learner autonomy, explore its potential as much as possible and make it serve as the catalyst in foreign language teaching and learning.

\section{Appendix}

\section{Questionnaire on Learner Autonomy}

Dear students,

I am doing some research on learner autonomy in modern languages learning and teaching. I would appreciate your cooperation with this questionnaire. The information given here will not be disclosed to any third party. The following questions are to know the students' related situations. Each of these items is followed by five alternatives on a 5-point Likert scale ranging from 1(strongly agree) to 5 (strongly disagree). Please answer them as honestly as possible.

Thank you for your cooperation.

$$
\begin{array}{lll}
\text { strongly agree } & \text { no view } & \text { strongly disagree } \\
& \text { agree } & \text { disagree }
\end{array}
$$

$\begin{array}{lllllll}\text { 1. I would like to learn by small group discussions. } & 1 & 2 & 3 & 4 & 5\end{array}$

2. I would like the students to participate in the class more. $\begin{array}{lllll}1 & 2 & 3 & 4 & 5\end{array}$

3. I would like to voice my opinions actively in class. $\quad \begin{array}{llllll}1 & 2 & 3 & 4 & 5\end{array}$

4. I don't regard the teacher as the authority. $\quad \begin{array}{lllll}1 & 2 & 3 & 4 & 5\end{array}$

$\begin{array}{lllllll}\text { 5. Knowledge should not be trans mitted by teachers. } & 1 & 2 & 3 & 4 & 5\end{array}$

Students should be active to learn and discover

knowledge by themselves.

6. I like the teacher to as sess my work.

$\begin{array}{lllll}1 & 2 & 3 & 4 & 5\end{array}$

7. I work hard for a practical purpose.

8. I think my progress mainly rest with myself.

9. I think it is necessary to make a study plan each term.

10. I like to work hard according to the study plan.

11. I like to preview the lesson before each class.

12. I like to review the lesson after each class.

$\begin{array}{ccccc}1 & 2 & 3 & 4 & 5 \\ 1 & 2 & 3 & 4 & 5 \\ 1 & 2 & 3 & 4 & 5 \\ 1 & 2 & 3 & 4 & 5 \\ 1 & 2 & 3 & 4 & 5 \\ 1 & 2 & 3 & 4 & 5\end{array}$


13. I like to find the gap after each test.

14. I like to learn by reading references

15. I like to learn by reading English magazines.

16. I like to learn by reading English newspapers.

17. I like to learn by reading English novels.

18. I like to learn by watching English TV and movies.

19. I like to learn by listening to English songs.

20. I like to perform item15-19 to broaden knowledge, enlarge vocabulary, understand more related culture.

21. I like to perform item15-19 for entertainment, pastime.

22. I like to perform item 15-19 to create harmonious atmosphere to learn English.

23. I think it is interesting to learn English.

24. I like to read the textbook repeatedly.

25. I often practice English with my friends.

26. I sometimes take part in English corner and benefit a lot from it.

27. I would learn English harder

if there are no examinations.

\section{BIBLIOGRAPHY}

[1] Arnold, J. 2000. Affect in Language Learning. Beijing: Foreign Language Teaching and Research Press.

[2] Benson, P. 1997. The Philosophy and Politics of Learner Autonomy. In P. Benson and P. Voller (Eds.). Autonomy and Independence in Language Learning. London: Longman.

[3] Benson, P. 2001. Teaching and Researching Autonomy in Language Learning. London: Longman.

[4] Chomsky, N. 1988. Language and Problems of Knowledge: the Nicaraguan Lectures. Cambridge, Mass.: MIT Press.

[5] Dickinson, L. 1987. Self-Instruction in Language Learning. Cambridge: Cambridge University Press.

[6] Gardner, D. 1996. Self-Assessment for Self-Access Learning. TESOL Journal 5(3) 18-23.

[7] Johnson, K. E. 1995. Understanding Communication in Second Language Classrooms. Cambridge: Cambridge

\begin{tabular}{|c|c|c|c|}
\hline 1 & 2 & 3 & \\
\hline 1 & 2 & 3 & \\
\hline 1 & 2 & 3 & 4 \\
\hline 1 & 2 & 3 & 4 \\
\hline 1 & 2 & 3 & 4 \\
\hline 1 & 2 & 3 & \\
\hline 1 & 2 & & \\
\hline
\end{tabular}

$\begin{array}{lllll}1 & 2 & 3 & 4 & 5\end{array}$

$\begin{array}{lllll}1 & 2 & 3 & 4 & 5\end{array}$

$\begin{array}{lllll}1 & 2 & 3 & 4 & 5\end{array}$

$\begin{array}{lllll}1 & 2 & 3 & 4 & 5\end{array}$

$\begin{array}{lllll}1 & 2 & 3 & 4 & 5\end{array}$

$\begin{array}{lllll}1 & 2 & 3 & 4 & 5\end{array}$

$\begin{array}{lllll}1 & 2 & 3 & 4 & 5\end{array}$

$\begin{array}{lllll}1 & 2 & 3 & 4 & 5\end{array}$

University Press.

[8] Little, D. 1995. Learning as Dialogue: The Dependence of Learner Autonomy on Teacher Autonomy. System 23(2): $175-81$.

[9] Littlewood, W. 1999. Defining and Developing Autonomy in East Asian Contexts. Applied Linguistics 20 (1): 71-94.

[10] Nunan, D. 1995. Closing the Gap between Learning and Instruction. TESOL Quarterly

[11] Nunan, D. 2002. Research Methods in Language Learning. Cambridge: Cambridge University Press.

[12] Wenden, A. 1998. Metacognitive Knowledge and Language Learning. Applied Linguistics. 19(4):515-37. 